\title{
Use of phage display antibodies for monitoring cytokine-induced priming of granulocytes in human peripheral blood
}

\author{
E. Fortunati ${ }^{\mathrm{a}, *}$, D. Kanters ${ }^{\mathrm{a}}$, J.W.J. Lammers ${ }^{\mathrm{a}}$, \\ J. de Kruif ${ }^{\mathrm{b}, \mathrm{c}}$, T. Logtenberg ${ }^{\mathrm{b}, \mathrm{c}}$ and \\ L. Koenderman ${ }^{\mathrm{a}}$ \\ ${ }^{\mathrm{a}}$ Dept. Pulmonary Disease and \\ bImmunology, University Medical Centre, Utrecht, \\ The Netherlands \\ ${ }^{\mathrm{c}}$ Utrecht Biotechnology Systems, Utrecht, The \\ Netherlands
}

The development of the phage display technique has led to the possibility of in vitro production of human antibodies. The most challenging medical application is their use in the identification of associated disease proteins. Our research interest is focused on the understanding of human granulocyte pre-activation (priming) in vivo. This process is extremely important in the control of host defence against pathogenic microorganisms. However, uncontrolled activation may lead to diseases such as adult respiratory stress syndrome and septic shock [1].

Granulocyte activation can be induced in vitro by the addition of pre-activating (priming) substances like cytokines, chemokines and/or bacterial products. After screening of a semi-synthetic phage antibody library of human scFv fragments, two human phage antibodies named MoPhab A17 and A27, were selected for their ability of recognising epitopes expressed on in vitro GM-CSF and TNF- $\alpha$ primed-granulocytes. Furthermore, these antibodies specifically bind to an epitope present on granulocytes of patients affected by obstructive pulmonary disease (COPD) or allergic asthma compared with healthy donors. These data support the use of the two antibodies as tools to study the priming process in vitro and to detect the progression of those widespread inflammatory diseases.

The poor performance of the MoPhab A17 and A27 in western blot and in immunoprecipitation hindered the identification of the epitopes expressed on primed granulocytes. An alternative approach, by means of human monoclonal antibodies obtained by conversion of phage-display library derived MoPhab A17 and A27 [2], is currently being investigated.

\section{References}

[1] H.L. Malech and J.I. Gallin, Current concept: immunology. Neutrophils in human diseases, N. Engl. J. Med. 317 (1987), 687-694.

[2] G.A. Huls et al., A recombinant, fully human monoclonal antibody with a antitumor activity constructed from phagedisplayed antibody fragments, Nat. Biotechnol. 17 (1999), 276281.

${ }^{*}$ Correspondence to: Elisabetta Fortunati, Department Pulmonary Diseases, University Medical Centre, Heidelberglaan 100, Post G.03.550, 3584 CX Utrecht, The Netherlands. Fax: +31302505414; E-mail: e.fortunati@hli.azu.nl. 


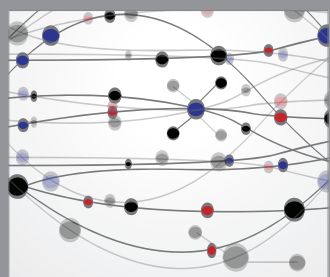

The Scientific World Journal
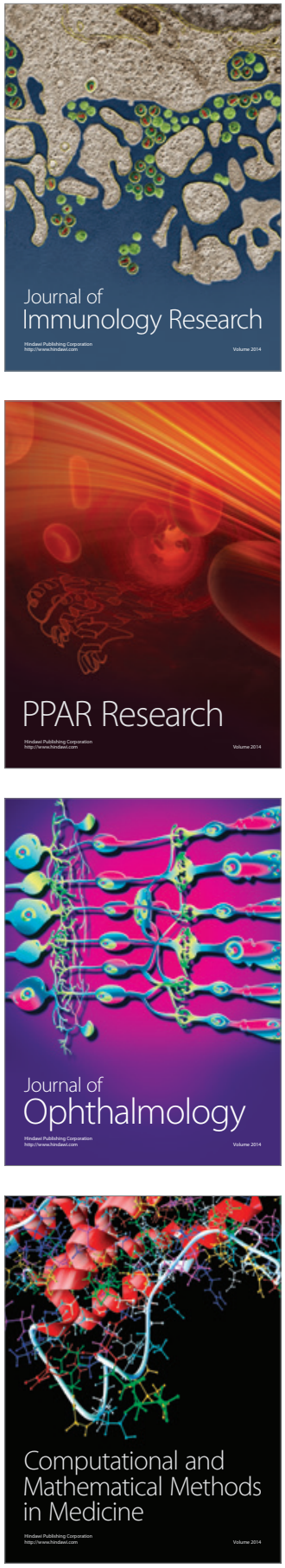

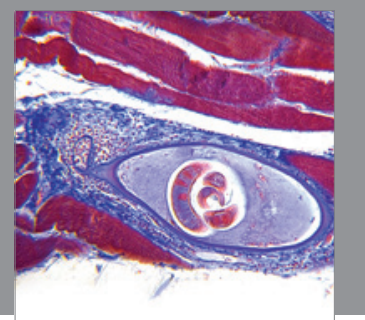

Gastroenterology

Research and Practice
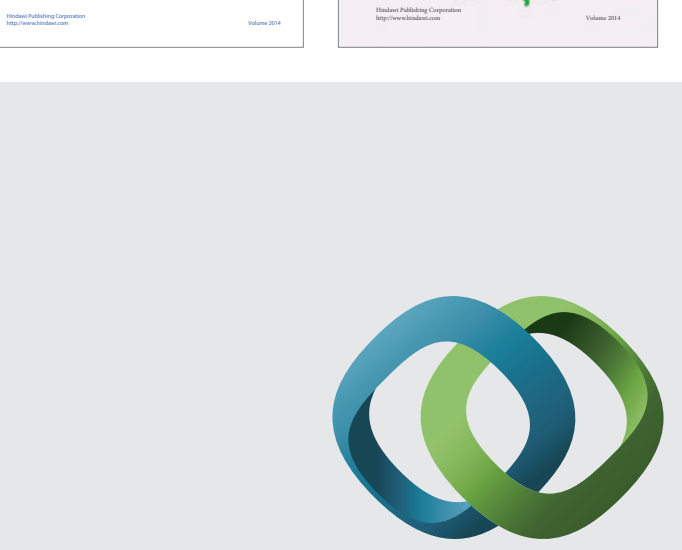

\section{Hindawi}

Submit your manuscripts at

http://www.hindawi.com
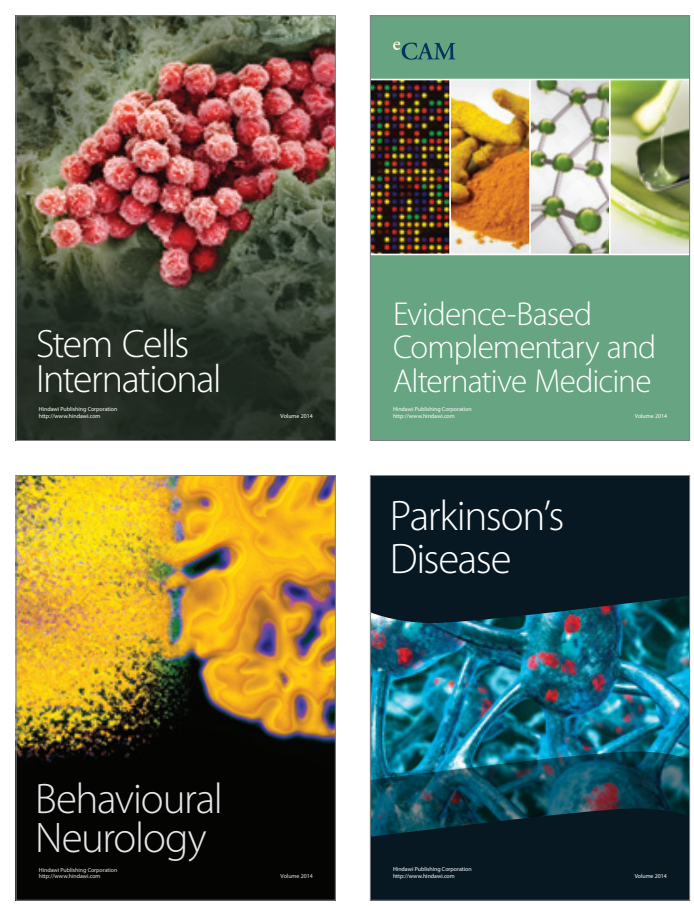

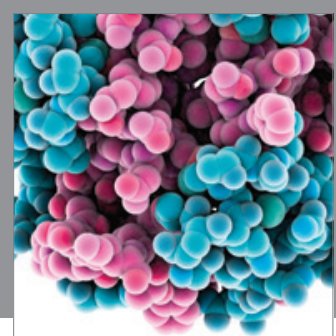

Journal of
Diabetes Research

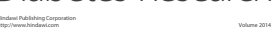

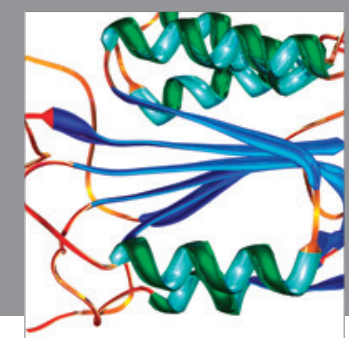

Disease Markers
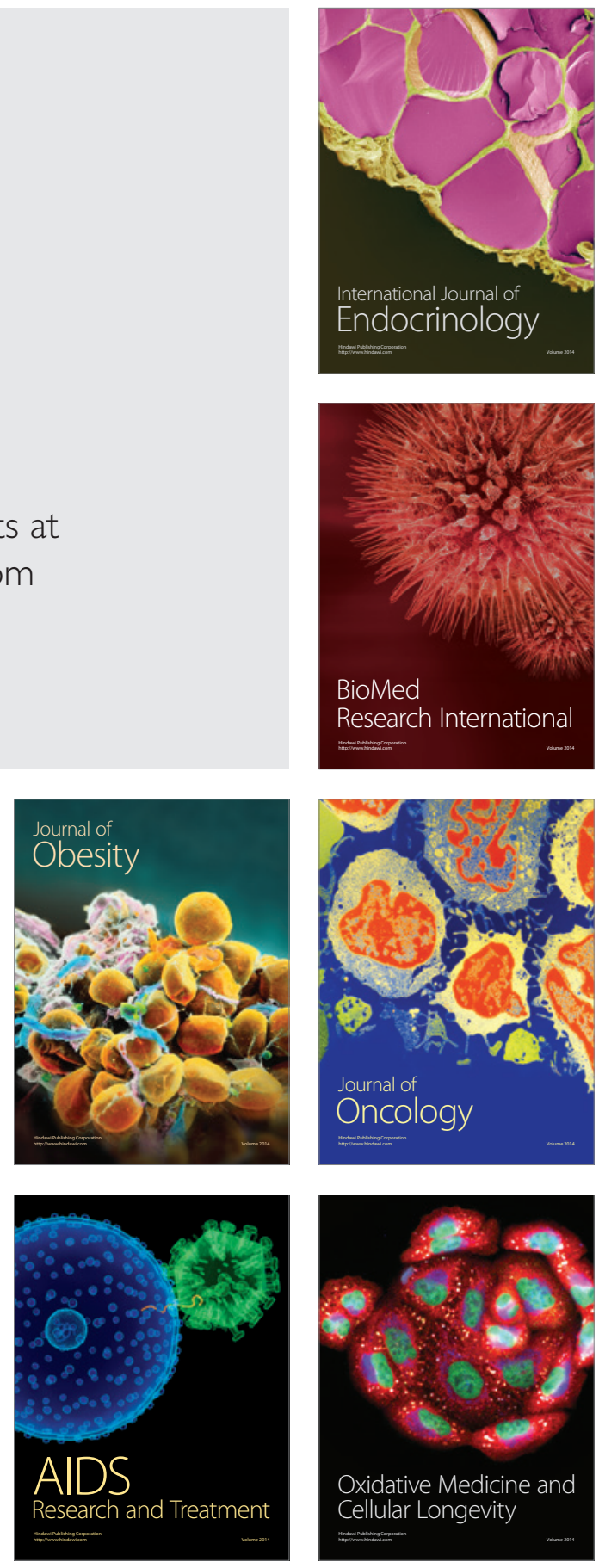